\title{
Circulating Chromogranin A and Catecholamines in Human Fetuses at Uneventful Birth
}

\author{
A. MOFTAQUIR-HANDAJ, F. BARBÉ, P. BARBARINO-MONNIER, D. AUNIS, \\ AND M. J. BOUTROY
}

\begin{abstract}
INSERM (Institut National de la Santé et de la Recherche Médicale) U272 Pathologie et Biologie du Développement Humain, Nancy, France [A.M.-H., F.B., P.B.-M., M.J.B.]; Unité de Médecine et

Réanimation Néonatales, et Laboratoire de Biologie Clinique, Maternité Régionale Universitaire de Nancy, France [A.M.-H., F.B., P.B.-M., M.J.B.]; and INSERM U338 Biologie de la Communication Cellulaire, Strasbourg, France [D.A.]
\end{abstract} \begin{abstract}
ABS
Chromogranin A (CGA), a large acidic $48-\mathrm{kD}$ protein, co-
stored and coreleased by exocytosis with catecholamines, has been shown to be a precursor of peptides that exert feedback regulatory control on catecholamine secretion. In plasma, CGA levels increase in response to a large-amplitude physical stimulation in adult subjects and may be related to catecholamine levels. Any akin information is not yet available when the sympathoadrenal system is highly actived during birth. This activation is strongly related to parturition circumstances such as the mode of delivery. The aim of our study was to determine CGA plasma levels in infants delivered vaginally or by elective cesarean section and to investigate the possible correlation between CGA and catecholamine concentrations. Plasma levels of catecholamines (norepinephrine and epinephrine) and CGA were assessed by HPLC with electrochemical detection and immunoenzymology, respectively. CGA and norepinephrine concen-
\end{abstract}

trations were significantly higher $(p<0.0002$ and $p<0.02)$ in infants vaginally born than in the group delivered by elective cesarean section. A significant relationship $(p<0.04)$ was found between CGA and norepinephrine levels. However, for epinephrine, no significant difference was found between both groups. These results demonstrate the fetus' ability to corelease CGA and norepinephrine massively in response to stress of birth. (Pediatr Res 37: 101-105, 1995)
CGA, chromogranin A
CS, cesarean section group
E, epinephrine
NE, norepinephrine
$\mathrm{V}$, vaginal group
DHBA, dihydroxylbenzylamine

Abbreviations
Catecholamine storage vesicles of the adrenal medulla and sympathetic nerves contain several proteins in addition to low molecular weight components such as catecholamines, ATP, calcium, and enkephalins. The soluble proteins include dopamine $\beta$-hydroxylase, a tetrameric glycoprotein that catalyzes the final step in the biosynthesis of NE and a group of acidic proteins collectively called chromogranins (1). CGA, well characterized from bovine adrenal medullary chromaffin granules, is the most abundant subclass of chromogranins (2). The polypeptidic chain of CGA comprises 431 amino acid residues corresponding to a 48-kd glycoprotein, the primary structure of which has already been established (3). CGA was originally thought to be restricted to the adrenal medulla, but it was later found to be similar, if not identical, to secretory protein I of the parathyroid gland (4). Subsequently, CGA and other subclasses of chromogranin have been found in most endocrine and

Received December 28, 1993; accepted July 25, 1994

Correspondence: Dr. M. J. Boutroy, INSERM U 272, 24-30 rue Lionnois, BP 3069 , 54013 Nancy, France.

Supported by INSERM financial participation. neuroendocrine cells within secretory granules in human beings and animals. CGA has a broad phylogenetic distribution in such evolutionarily divergent species as mammals, fishes, birds, and amphibians, with a remarkable preservation of epitopes and molecular size (5). The ubiquitous occurrence of CGA suggests important biologic roles for this protein. Recent data have brought forward that CGA is a precursor of several peptides including pancreastatin and chromostatin. Pancreastatin, a 49-residue peptide, has been described in porcine pancreas as a potent inhibitor of insulin secretion from endocrine pancreatic islets (6). CGA-derived peptides have been found to exert a feedback control on chromaffin cell secretory activity (7-9), and chromostatin, a 20-residue peptide, inhibits endothelin-1-induced vasoconstriction in human blood vessels (10).

CGA and catecholamines are coreleased by exocytosis from the same storage vesicules of chromaffin cells. Both of them are found in the peripheral bloodstream. Moreover, CGA levels were reported to be increased in the same physiologic and pathologic states as were catecholamines: physical exercise, hypertension, pheochromocytoma (11). Correlations between 
CGA and NE plasma levels have been observed in a wide range, reflecting the large variety of clinical situations and the different intensities of sympathoadrenal stimulation. Inasmuch as CGA seems to be an interesting biochemical marker for catecholamine exocytosis and a useful clue of sympathoadrenal activity, it seemed interesting to examine the particular situation of the sympathoadrenal activation in the fetus during parturition, namely birth-induced stress. It has been shown that plasma catecholamine levels are considerably high at birth (12) mediating vital processes of the perinatal events. They are influenced by the mode of delivery, being lower after elective cesarean section than after vaginal delivery (13), but in the same range when the cesarean section is performed during labor (14).

The aim of this study was to measure CGA levels in infants delivered vaginally or by elective cesarean section to assess whether a difference exists between the two groups and whether a correlation can be established with either NE or E levels.

\section{METHODS}

\section{Subjects}

Twenty full-term infants were studied in the Department of Obstetrics and Gynecology C (Maternité Régionale Universitaire de Nancy). Their characteristics are shown in Table 1. They were all delivered after uncomplicated pregnancies and appropriate for their gestational age according to Usher and McLean's nomograms (15). Infants with an umbilical $\mathrm{pH}$ less than 7.25 or suffering with any pathology were excluded. The studied infants were divided in two groups: the V group, 13 infants delivered vaginally; and the CS group, seven infants delivered by elective cesarean section under general anesthesia induced with thiopental $(4 \mathrm{mg} / \mathrm{kg}$ ) who had intubation performed under suxamethonium iodure $(1.5 \mathrm{mg} / \mathrm{kg})$ apnea.

At birth, blood samples were collected in heparinized iced tubes (Vacutainer, Becton Dickinson SA, Pont de Claix, France) from umbilical arteries of a double-clamped cord segment as soon as the newborn was delivered. After centrifugation, plasma was immediately separated and frozen at $-80^{\circ} \mathrm{C}$ until subsequent analysis.

The study protocol was approved by the local ethical committee and the mothers gave their informed consent. A group of 24 healthy resting adults was tested for CGA concentration measurements.

\section{Catecholamine Measurements}

$\mathrm{NE}$ and E were analyzed by HPLC with electrochemical detection (16).

Instrumentation. The chromatographic system consisted of a pump Varian 5000 (Varian S.A., les Ulis, France) with an injection valve (Valco Instruments, Houston, TX) equipped with a $20-\mu \mathrm{L}$ loop and a $\mathrm{C}_{18}$ column $150 \times 3.9 \mathrm{~mm}$ (Resolve $\mathrm{C}_{18}$, Waters, Millipore SA, Molsheim, France) placed in loop position. The detection system was a thin-layer electrochemical detector (Waters 460) provided with a carbon electrode maintained at $+0.6 \mathrm{~V}$ potential versus a $\mathrm{Ag} / \mathrm{AgCl}$ reference
Table 1. Clinical characteristics

\begin{tabular}{lcc}
\hline & V group $(n=13)$ & CS group $(n=7)$ \\
\hline Gestational age (wk) & $39.4 \pm 0.4$ & $38.8 \pm 0.6$ \\
Birth weight (kg) & $3.1 \pm 0.5$ & $2.9 \pm 0.6$ \\
Apgar score (1 min) & $8.9 \pm 0.2$ & $8.3 \pm 0.2$ \\
Blood pH & $7.36 \pm 0.01$ & $7.35 \pm 0.03$ \\
\hline
\end{tabular}

$\mathrm{V}$, vaginal; $\mathrm{CS}$, cesarean section; data given as mean \pm 1 SEM.

electrode. The detector was mounted within its proper Faraday cage and its output was connected to a recorder Perkin Elmer 56 (Perkin Elmer S.A., Bois-d'Arcy, France).

Chemicals and solvents. $\mathrm{NE}$ and $\mathrm{E}$ as well as the internal standard DHBA were provided by Sigma Chemical Co. (St. Louis, MO). The $0.03 \mu \mathrm{mol} / \mathrm{L}$ standard solutions were prepared in $0.3 \mathrm{M} \mathrm{HClO}_{4}$ and stored at $-80^{\circ} \mathrm{C} ; 2 \mathrm{M}$ Tris- $\mathrm{HCl}$ buffer, $\mathrm{pH} 8.8$, and sodium meta-bisulfite were purchased from Merck (Darmstadt, Germany). The alumina cartridges were provided by Waters.

Chromatographic conditions. The mobile phase consisted of $8 \%(\mathrm{vol} / \mathrm{vol})$ methanol Rs HPLC (LiChrosolv), $0.1 \mathrm{M}$ phosphate buffer $\mathrm{Na}_{2} \mathrm{PO}_{4}$ (Merck), $0.52 \mathrm{mM}$ octane sulfonic acid sodium salt (Sigma) and $0.05 \mathrm{mM}$ EDTA disodium salt (Sigma). The $\mathrm{pH}$ of the mobile phase was adjusted to 4.5 . The flow rate was $0.8 \mathrm{~mL} / \mathrm{min}$ and the run time was $20 \mathrm{~min}$. The applied voltage was $0.6 \mathrm{~V}$.

Sample preparation. Catecholamine extraction was performed at $+4^{\circ} \mathrm{C}$ by adsorption on alumina according to classic method without deproteinization. In $10-\mathrm{mL}$ alumina cartridges, to $100 \mu \mathrm{L}$ of plasma were added $100 \mu \mathrm{L}$ of a mixture of a $5 \%$ $(0.13 \mathrm{M})$ EDTA (Sigma) solution and a $1 \%(53 \mathrm{mM})$ sodium bisulfite (Merck) solution, $50 \mu \mathrm{L}$ of DHBA $(0.03 \mu \mathrm{mol} / \mathrm{L})$ used as an internal standard, and $200 \mu \mathrm{L}$ of $2 \mathrm{M} \mathrm{HCl}$ Tris, $\mathrm{pH}$ 8.8. The cartridges were capped and placed on a reciprocal shaker for $15 \mathrm{~min}$ at $+4^{\circ} \mathrm{C}$. The supernatant was discarded, and alumina was washed three times with bidistilled cold water. The washings were removed out by aspiration. After the last wash, catecholamines were eluted from the alumina with $50 \mu \mathrm{L}$ of $0.3 \mathrm{M} \mathrm{HClO}_{4}$. The cartridges were centrifuged at $4^{\circ} \mathrm{C}$ for $1 \mathrm{~min}$. All eluates were put into small Eppendorf vials and placed in the dark at $4^{\circ} \mathrm{C}$ until the assay. A $20-\mu \mathrm{L}$ eluate sample was injected in the chromatographic system.

Calculation. NE and E concentrations were calculated by measuring the ratio NE or E peak height/DHBA peak height and comparing this to the peak height ratios for the synthetic standards assayed following the same procedure and whose original concentration was known $(0.03 \mu \mathrm{mol} / \mathrm{L})$ : $[\mathrm{NE}]$ in sample $=(\mathrm{NE} / \mathrm{DHBA})_{\text {sample }} /(\mathrm{NE} / \mathrm{DHBA})_{\text {standard }} \times[\mathrm{DHBA}]$.

Chromatographic performance. The detection limit defined as the amount of catecholamines leading to a signal/noise ratio of 3 was $25 \mathrm{pg}$ for NE, $50 \mathrm{pg}$ for E, and $30 \mathrm{pg}$ for DHBA. The reproducibility, which was tested by repeated measurements of $\mathrm{NE}$ and $\mathrm{E}$ at a 6-d interval, was estimated using the coefficient of variation percentage of NE $(4.5 \%)$ and of $E(5.9 \%)$. The recovery percentage was estimated to be $53-57 \%$.

\section{CGA Measurements}

The quantitative determination of CGA in plasma was performed using a solid-phase enzyme immunoassay (CGA 
ELISA, DAKO, Trappes, France). This consisted of a double antibody sandwich assay where samples and peroxidaseconjugated anti-CGA were incubated simultaneously in microwells coated with anti-CGA. The assay used rabbit antibodies to the human CGA 23-kd C-terminal fragment.

In the assay, CGA standard and samples were prediluted in buffer and added with peroxidase-conjugated anti-CGA to microwells precoated with anti-CGA. During a 2-h incubation period, a sandwich was formed consisting of solid-phase antibody, CGA, and the peroxidase-conjugated antibody. After a washing step, where unbound material was removed, a chromogenic substrate was added to wells. The more CGA present in the sample, the more intense the blue color that developed. The color development was stopped by acidification. The absorbance at $450 \mathrm{~nm}$ was measured using a microplate reader (Molecular Devices, Vmax Kinetic Microplate, Menlo Park, CA).

The detection limit of the method was determined by the mean absorbance of the $0 \mu \mathrm{g} / \mathrm{L} \pm 2 \mathrm{SD}$ and was estimated to be $2 \mu \mathrm{g} / \mathrm{L}$. The measuring range was from 10 to $500 \mu \mathrm{g} / \mathrm{L}$. The recovery ranged between 95 and $100 \%$ and the imprecision between 7 and $9 \%$.

\section{Statistical Analysis}

Results are reported as mean \pm 1 SEM. Data were analyzed using statistical analysis performed on StatView SE Graphics software (Abacus Concepts Inc., 1988, Neylan, France) on an LC Macintosh computer. Intergroup comparisons of mean values were made by a $t$ test. Because the values were not normally distributed, we used their natural logarithm transformation. The different relationships were determined using the correlation factor calculation. The threshold of significance was $5 \%$.

\section{RESULTS}

The CGA plasma concentrations were different according to the mode of delivery: levels were significantly $(p<0.0002)$ higher in the V group $(n=13 ; 37.6 \pm 3.4 \mu \mathrm{g} / \mathrm{L})$ than in the CS group $(n=7 ; 23.7 \pm 2.8 \mu \mathrm{g} / \mathrm{L})$. These concentrations were also significantly higher than those of resting adults $(n=24$; $8.8 \pm 1.2 \mu \mathrm{g} / \mathrm{L}$ ), regardless of whether the infants were born by vaginal or cesarean delivery $(p>0.0004$ and 0.0001$)$ (Fig. 1).

The plasma NE concentrations were higher $(p<0.02)$ in infants delivered vaginally $(n=13 ; 30.4 \pm 9.2 \mathrm{nmol} / \mathrm{L})$ than in those delivered by elective cesarean section $(n=7 ; 6.5 \pm$ $1.3 \mathrm{nmol} / \mathrm{L}$ ). However, there was no significant difference in $\mathrm{E}$ levels in both groups $(8.5 \pm 2.7 \mathrm{nmol} / \mathrm{L}$ versus $3.5 \pm 1.0$ $\mathrm{nmol} / \mathrm{L}$ in the $\mathrm{V}$ and $\mathrm{CS}$ groups, respectively).

CGA was significantly correlated with NE levels $(r=0.45$; $p<0.04$ ) when the subjects of both groups were included (Fig. 2). Neither NE nor CGA levels were related to venous blood $\mathrm{pH}$.

\section{DISCUSSION}

In our study, plasma catecholamine levels at birth were in the same range as those previously published confirming the

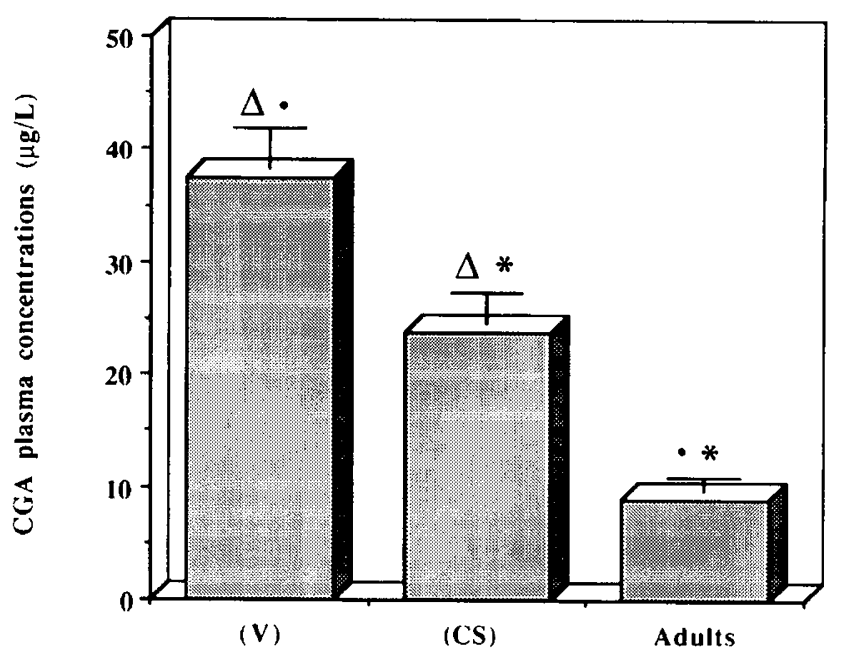

Figure 1. Comparison of $\mathrm{V}$ and elective $\mathrm{CS}$ and adult CGA levels (mean \pm 1 SEM). Statistical analysis reveals a significant difference between $\mathrm{V}$ and CS CGA levels $(\Delta, p<0.0002)$. CGA concentrations are significantly higher in neonates than in adults $\left(\boldsymbol{O}, p<0.0004\right.$; $\left.^{*}, p<0.0001\right)$.

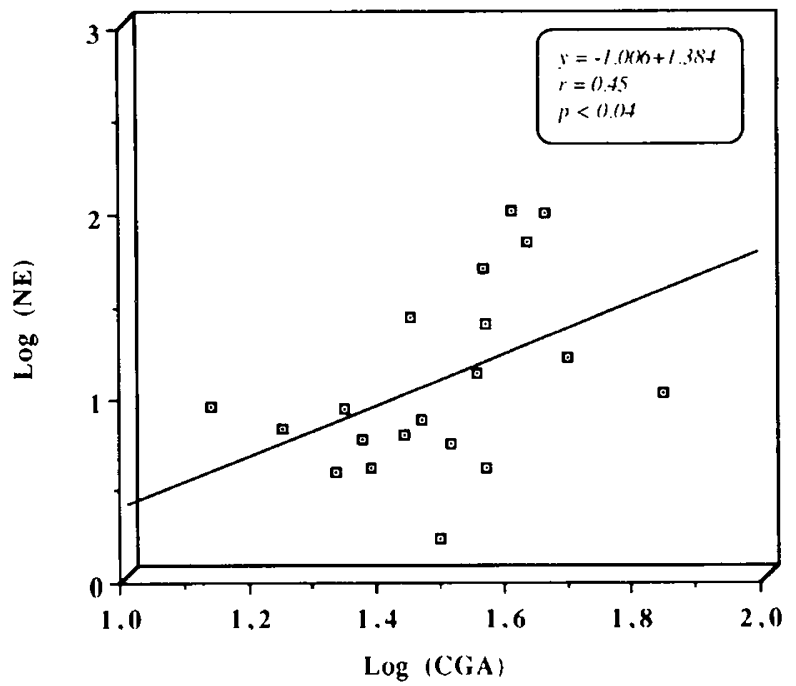

Figure 2. Relationship between CGA and NE levels in neonates. CGA and NE concentrations are significantly correlated $(r=0.45 ; p<0.04)$.

large discrepancy of physiologic states between infants born vaginally and those born after elective cesarean section $(12,13$, 17-19). For NE, this difference was clear, and the concentrations were significantly higher in the first group than in the second one; for $\mathrm{E}$, the difference was less evident, probably owing to the wide scatter of individual values and the small size of groups. A similar pattern has been shown for CGA, because the levels were much more higher in the group delivered vaginally than in the other one. Because CGA and NE are costored and coreleased (20), the relationship between CGA and NE levels could be an additional argument to look at CGA as a peripheral clue of sympatho-adrenergic stimulation in the fetus and the newborn, as it is becoming in adults (21).

These data raise again the complex question of the mechanisms by which such a fantastic surge in circulating catecholamines can be triggered and regulated in such young subjects, and also how they can sustain it without severe consequences for their life. 
The sympatho-adrenergic system is the main piece to withstand the stress of birth. Evidence gathered by numerous authors, among which Lagercrantz and coworkers have done a pioneering work, has established that the catecholamine release plays a vital role in adaptation to events of parturition and immediate extrauterine life by surviving oxygen deprivation, promoting breathing and absorption of lung liquid, and speeding up the metabolic rate $(12,22,23)$.

Chromaffin tissues are functional even before the anatomic maturity is reached. Very early in fetal life, typical chromaffin reaction can be detected in developing chromaffin tissue, but the time of its appearance seems to vary considerably from one species to another (24). In fetal rabbit, this was first observed at $20 \mathrm{~d}$, i.e. at two thirds of gestation. In human fetuses, immunostaining for tyrosine hydroxylase was found in adrenal primordia as early as $9 \mathrm{wk}(25)$, and the fetal secretion of catecholamines has been documented at 21 wk of gestational age by in utero cord sampling (26). Sources of circulating catecholamines at birth are represented by spillover from not only postganglionic sympathetic neurons and adrenal medulla, but also from extraadrenal tissue, also known as paraaortic tissue, namely organs of Zuckerkandl particularly well developed in rat, rabbit, guinea pig, and humans during fetal and neonatal life. These tissues are very sparsely innervated (or not innervated at all), and, as described for human or rat noninnervated adrenals (23), they produce catecholamines by a direct response to hypoxia or other stressors. The ability of chromaffin tissues to develop a "nonneurogenic" response is essential for the fetal life during which the fetus grows under relatively low oxygen conditions and for survival during uterine contractions of parturition when the compression of the placenta and of the umbilical cord intermittently deprives the infant of oxygen (27).

Another point, much less documented, of the physiologic adaptation at birth must be considered, i.e. the biologically active proteins and neuropeptides present in the chromaffin tissues. These include enkephalins, substance $P$, vasoactive intestinal peptide, neuropeptide $\mathrm{Y}$, and CGA costored and coreleased with catecholamines in adult subjects. A significant role for some of these peptides has been demonstrated on bovine chromaffin cells: enkephalins and susbstance $P$ inhibit the nicotine-induced release of catecholamines $(28,29)$; this is also the case with CGA-derived peptides (7). In the fetus, they are present in the adrenal medulla at least from midgestation. Some of them, such as neuropeptide $Y$, have been found in blood of infants. Lundberg et al. (30) observed higher levels of neuropeptide $\mathrm{Y}$-like immunoreactivity in full-term infants born vaginally than after cesarean section, and they reported a fair correlation between neuropeptide Y-like immunoreactivity and catecholamines levels. They concluded that this peptide exerting both inhibitor effects on NE release and vasoconstrictor effects may play a role together with catecholamines in stress reaction at birth.

We have been interested by CGA, because it was demonstrated that this prohormone was able to exert not only a feedback regulation on catecholamine release but also a direct effect on human blood vessels by inhibiting vasoconstriction produced by endothelin-1 (10). Moreover, the N-terminal pep- tide (1-40) stimulates the secretion of calcitonin gene-related peptide, the vasodilatative functions of which are well known. It seems evident that CGA possesses some functions targeted to vasodilation and is thus able to counteract the vascular constrictor effects of catecholamines and active peptides when they are secreted in excess. Inasmuch as in human fetúses a positive reaction for CGA (25) and CGA mRNA was observed in adrenal primordia as early as 6 to $8 \mathrm{wk}$ of gestational age, we hoped to find measurable amounts of CGA in full-term infants' blood, as is the case in adults when sympathoadrenal stimulation occurs (31). The present finding has confirmed this hypothesis, and we observed for CGA a pattern of difference in plasma levels according to the mode of delivery similar to that previously found by others for catecholamines and neuropeptide $Y$. In addition, whatever may be the mode of delivery, CGA levels in infants were found to be much more elevated than in adults, evidence of an unusual and sustained high level of sympathoadrenal stimulation in full-term neonates.

Our study has shown the correlation of CGA and NE levels in the bloodstream of infants in response to stress of birth, revealing the corelease of CGA and NE. Due to lack of available information, we are not yet able to answer to the following questions: 1 ) Are extraadrenal chromaffin tissues involved in birth CGA release? 2) Are there functional NEproducing cells in the fetal human adrenal medulla? The full understanding of mechanisms involved in regulation and adaptation at birth requires answers to these questions.

Acknowledgments. The authors thank Danièle Thiersé for helpful technical advice and J. L. Boutroy for having encouraged us to collect the patients in his Department of Obstetrics.

\section{REFERENCES}

1. Blaschko H, Comline RS, Schneider FH, Silver M, Smith AD 1967 Secretion of a chromaffin granule protein, chromogranin, from the adrenal gland after splanchnic stimulation. Nature 215:58-59

2. Winkler H 1976 The composition of the adrenal chromaffin granules: an assessment of controversial results. Neuroscience 1:65-80

3. Benedum UM, Baeuerle PA, Konecki DS, Frank R, Powell J, Mallet J, Huttner WB 1986 The primary structure of bovine chromogranin A: a representative of class of acidic secretory proteins common to a variety of peptidergic cells. EMBO J 5:14951502

4. Ahn TG, Cohn DV, Gorr SU, Ornstein DL, Kashdan MA, Levine MA 1987 Primary structure of bovine pituitary secretory protein I (chromogranin A) deduced from the cDNA sequence. Proc Natl Acad Sci USA 84:5043-5047

5. Rieker S, Fisher-Colbrie R, Eiden L, Winkler H 1988 Phylogenetic distribution of peptides related to chromogranins A and B. J Neurochem 50:1066-1073

6. Tatemoto K, Efendic S, Mutt V, Makk G, Feistner GJ, Barchas JD 1986 Pancreastatin, a novel pancreatic peptide that inhibits insulin secretion. Nature 324:476-478

7. Simon JP, Bader MF, Aunis D 1988 Secretion from chromaffin cells is controlled by chromogranin A-derived peptides. Proc Natl Acad Sci USA 85:1712-1716

8. Simon JP, Bader MF, Aunis D 1989 Proteolytic processing of chromogranin A in cultured chromaffin cells. Biochim Biophys Acta 1051:123-130

9. Galindo E, Rill A, Bader MF, Aunis D 1991 Chromostatin, a 20-amino acid peptide derived from chromogranin A, inhibits chromaffin cell secretion. Proc Natl Acad Sci USA 88:1426-1430

10. Aardal S, Galindo E, Aunis D, Helle KB 1993 Human chromostatin inhibits endothelin-1-induced contractures in human blood vessels. Regul Pept 47:25-32

11. O'Connor DT, Takiyyuddin MA, Cervenka JH, Parmer RJ, Barbosa JA, Chang YM, Hsiao RJ 1990 Circulating chromogranin A as a diagnostic tool in clinical chemistry. Acta Histochem Suppl 38:27-33

12. Lagercrantz H, Bistoletti P 1977 Catecholamine release in the newborn infants at birth. Pediatr Res 11:889-893

13. Irested L, Lagercrantz H, Hjemdahl P, Hägnevik K, Belfrage P 1982 Fetal and maternal plasma catecholamine levels at elective cesarean section in general and epidural anesthesia versus vaginal delivery. Am J Obstet Gynecol 142:1004-1010

14. Eliot RJ, Lam R, Leake R, Hobel CJ, Fisher DA 1980 Plasma catecholamine concentrations in infants at birth and during the first 48 hours of life. J Pediatr $96: 311-315$ 
15. Usher R, McLean F 1969 Intrauterine growth of live-born Caucasian infants at sea level: standards obtained from measurements of 7 dimensions of infants born between 25 and 44 wk of gestation. J Pediatr 74:901-910

16. Davis GC, Kissinger PT 1981 Strategies for determination of serum or plasm norepinephrine by reverse phase liquid chromatography. Anal Chem 53:165-169

17. Padbury JL, Roberman B, Oddie TH, Hobel CJ, Fisher DA 1982 Fetal catecholamine release in response to labor and delivery. Obstet Gynecol 60:607-611

18. Bistoletti P, Nisell H, Palme C, Lagercrantz H 1981 Term breech delivery. Act Obstet Gynecol Scand 60:165-171

19. Lagercrantz H, Bistoletti P, Lunell NO 1979 Catecholamine release in the human fetus and newborn infant. In: Catecholamines: Basic and Clinical Frontier. Pergamon Press, New York, pp 912-914

20. Winkler H, Fischer-Colbrie R 1992 The chromogranins A and B: the first 25 year and future perspectives. Neuroscience 49:497-528

21. Dimsdale JE, O'Connor DT, Ziegler M, Mills P 1992 Chromogranin A correlates with norepinephrine release rate. Life Sci 51:519-525

22. Padbury JF, Martinez AM 1988 Sympatho adrenal system activity at birth: integration of postnatazl adaptation. Semin Perinatol 12:163-172

23. Lagercrantz H, Slotkin TA 1986 The "stress" of being born. Sci Am 254:92-102

24. Coupland RE 1965 The Natural History of the Chromaffin Cell. Longmans, London
25. Molennar WN, Lee VMY, Trojanowskija JQ 1990 Early fetal aquisition of the chromaffin and neural immunophenotype by human adrenal medullary cells: an immunohistochemical study using monoclonal antibodies to chromogranin A synaptophysin, tyrosine hydroxylase and neural cytoskeletal protein. Exp Neurol 108:1-9

26. Weiner CP, Robillard JE 1988 Atrial natriuretic factor, digoxin-like immunoreactive substance, norepinephrine, epinephrine, and plasma renin activity in human fetuses and their alteration by fetal disease. Am J Obstet Gynecol 159:1353-1360

27. Slotkin TA, Seidler FJ 1988 Adrenomedullary catecholamine release in the fetus and the newborn: secretory mechanisms and their role in stress and survival. J Dev Physiol 10:1-16

28. Kumara K, Karoum F, Guidotti A, Costa E 1980 Modulation of nicotinic receptors by opiate receptor agonists in cultured adrenal chromaffin cells. Nature 283:489-492

29. Mizobe F, Kozousek V, Dean DM, Livett BG 1979 Pharmacological characterization of adrenal paraneurons: substance $P$ and somatostatin as inhibitory modulators of the nicotinic response. Brain Res 178:555-566

30. Lundberg JM, Hemsén A, Fried G, Theodorsson-Norheim E, Lagercrantz H 1986 Co-release of neuropeptide Y (NPY)-like immunoreactivity and catecholamines in newborn infants. Acta Physiol Scand 126:471-473

31. Elias AN, Wilson AF, Pandian MR, Kayaleh R 1992 Chromogranin A concentrations in plasma of physically active men after acute exercise. Clin Chem 38:2348-2349 